\title{
$\mathrm{DEA}$ 를 활용한 자동차부품 기업의 효율성 평가에 관한 연구 \\ 조형국 ${ }^{1}$, 이철규 ${ }^{*}$, 유왕진 ${ }^{1}$ \\ ${ }^{1}$ 건국대학교 일반대학원 벤처전문기술학과, \\ ${ }^{2}$ 건국대학교 신산업융합학과
}

\section{A Study on the Efficiency Analysis for the Automotive Parts Manufacturer Using Data Envelopment Analysis}

\author{
Cho, Hyung-Kook ${ }^{1}$, Lee, Cheol-Gyu ${ }^{2^{*}}$ and Yoo, Wang-Jin ${ }^{1}$ \\ ${ }^{1}$ Dept. of Venture Technology and Management, Konkuk University \\ ${ }^{2}$ Dept. of Advanced Industry Fusion, Konkuk University
}

\begin{abstract}
요 약 최근 글로벌 경기 침체로 인한 완성차 수요 급감으로 세계 자동차부품산업이 위기에 직면해 있다. 미국 자 동차부품업체들은 2008년 4분기 이후 대규모 적자를 기록 중에 있으며, 고성장세를 유지하던 일본 및 유럽 부품업체 들도 경영실적이 크게 악화되었다. 국내 자동차부품기업도 이러한 영향에서 벗어나기가 어려울 것으로 예상된다. 본 연구는 자동차부품 중소기업 중 상장된 25 개의 업체를 대상으로 DEA분석기법을 활용하여 각 기업에 대한 상대적 효 율성을 분석하였다. 효율성분석결과 CCR모델에서는 전체 25 개 기업 중 6 개 기업이 효율적인 것으로 나타났지만 기 업의 규모를 고려한 효율성 분석인 $\mathrm{BCC}$ 분석결과 12 개 기업이 효율적으로 운영하는 것으로 나타났다. 그리고 25 개의 자동차부품기업 중 효율성이 1 인 기업이 DMU $1,5,7,10,18,24$ 로, 다른 자동차부품기업이 상대적으로 벤치마킹을 해야 할 대상은 DMU $1,10,24$ 로 나타났다. 본 연구의 결과를 바탕으로 국내 자동차부품기업이 나가야 할 방향을 제시하고, 국내 자동차부품기업의 효율성을 실증적으로 분석하여 경영효율성을 제고함으로써 향후 자동차부품기업을 경영하는데 있어 매우 중요한 정보를 제공할 것으로 기대된다.
\end{abstract}

\begin{abstract}
Due to the recent global recession, the car industry demand levels have plummeted which led to a crisis in the automotive parts industry for the first time in history. Since the fourth quarter of 2008, the automotive parts manufacturers in America have faced a record loss and those in Japan and Europe who also had a strong track record are facing a weak economy. In addition, the domestic automotive parts industry is also affected by the global economic crisis.

This research is that the relative efficiency analysis utilizing the DEA has done on the object of 25 small and medium-sized automotive parts manufacturers publicly listed, As the efficiency analysis result 6 of 25 manufacturers are efficient in CCR model and 12 manufactures have shown efficiency in BCC model, the efficiency analysis in consideration of the manufacturer size. The manufacturers with efficiency 1 in 25 manufacturers are DMU 1, 5, 7, 10, 18, 24 and the relatively benchmarking objects in other manufactures are DMU 1, 10, 24, Based on the results of this research, a direction to the domestic automotive parts manufacturers as well as a significant information will be provided in managing the companies in the future by the improvement of management efficiency through the practical efficiency analysis.
\end{abstract}

Key Words : Automotive Parts Manufacturer Efficiency, DEA : Data Envelopment Analysis

"이 논문은 2013년도 건국대학교 학술진흥연구비 지원에 의한 논문임"

"Corresponding Author : Lee, Cheol-Gyu(Konkuk Univ.)

Tel: +82-2-2049-6048 email: cglee@konkuk.ac.kr

Received October 17, 2013 Revised (1st November 26, 2013, 3rd December 4, 2013)

Accepted February 5, 2014 


\section{1. 서론}

국내 자동차 부품산업도 글로벌 경기 침체로 인한 영 향을 받고 있으며, 완성차 1 개 업체와 거래를 직접하고 있는 납품업체가 2008년 기준 445개(50.1\%)에 달하며, 글로벌 경기가 지속적으로 침체 시에는 자동차부품기업 에 직접적인 영향이 미칠 것으로 예상된다. 또한, 한화금 융경제연구소[1]에 의하면 미국의 경기 회복세 지연, 유 럽 침체 지속, 브릭스의 성장세 위축 등으로 국내 자동차 부품산업의 성장이 다소 둔화되고 있는 것으로 나타났으 며, 완성차의 내수판매 부진으로 성장세가 둔화될 것으로 예상하고 있다.

따라서 본 연구의 목적을 정리하면 다음과 같다. 첫째, 중소기업을 대상으로 자동차 부품산업에 대한 효율성을 분석한다. 둘째, 선행연구를 바탕으로 한 자동차부품기업 의 효율성을 정량적으로 평가한다. 셋째, 상대적 효율성 평가로 인한 벤치마킹을 통하여 글로벌 경기침체 시에도 경영실적 향상에 도움을 주고자 한다.

본 연구에서는 2013년 8월 기준 코스피 및 코스닥에 상장된 자동차 부품기업을 대상으로 동종 기업과의 효율 성을 $\mathrm{DEA}$ 분석기법을 이용하여 평가하고자 한다. 선행 연구를 바탕으로 자동차 부품기업의 특징을 도출하였다. 본 연구에서는 선행연구에 의해 투입변수와 산출변수를 정의하고, DEA 분석은 NICE신용평가정보의 KISVALUE에서 제공하는 재무 데이터를 기반으로 한 상 대적 효율성을 측정하였다. 또한 기본적인 $\mathrm{DEA}$ 모델이 갖는 단점을 보완한 초효율성 $\mathrm{DEA}$ 모델을 통해 효율성 을 산출하였다. 초효율성 DEA 모델은 효율성 점수가 1 로 효율적 기업들 간에 비차별적으로 평가되는 단점을 보완한 분석방법으로 효율적 기업들에게 1 이상의 효율성 값을 제공한다. 이러한 초효율성 값을 기반으로 국내 중 소자동차 부품기업의 순위 분석을 실시하였다.

\section{2. 본론}

\section{1 자동차부품산업에 관한 이론적 고찰 \\ 2.1.1 자동차부품산업의 정의 및 분류}

한국표준산업분류에 의하면, 자동차부품산업은 자동 차용 브레이크, 클러치, 축, 기어, 변속기, 휠, 완충기, 방 열기, 소음기, 배기관, 운전대 및 운전박스 등과 같은 자 동차, 차체 또는 자동차 엔진용 부분품을 제조하는 산업 활동으로 정의하고 있다.

자동차부품산업은 각종 자동차용 부품을 생산하여 완 성차업계에 공급하는 역할을 하는 산업으로 1 차 부품업
체와 1 차 부품업체에 부품을 납품하는 2 차 및 3 차 이상 의 부품업체로 구성된다. 통상 자동차 1 대를 생산하기 위 해서는 2 만개 이상의 다종다양한 부품이 소요되고 있으 며, 자동차에 대한 안정성과 편리성 추구로 전장화가 가 속화되고 있어 부품의 수는 더 많아지고 있는 추세이다. 이 중 자동차부품산업으로 분류되는 것은 자동차 생산에 필수불가결한 전용부품에 한정되므로 자동차용 유리, 범 용 전기전자부품 및 도료 등은 자동차관련 산업의 범주 에서 제외하는 것이 일반적이다. 타이어 산업의 경우 교 체용 타이어의 비중이 높아 자동차산업과의 상관관계가 떨어지고 있는 추세이고 산업규모 역시 크게 성장하여 별도의 산업으로 분류하고 있다.

\subsection{2 자동차부품산업에 관한 선행연구}

육근호[2]에 의하면 상장된 제조기업을 대상으로 연구 개발비가 기업가치에 미치는 효과를 연구하였다. 분석결 과 연구개발비는 기업가치에 정(+)의 영향을 미쳤으며, 특이한 점은 경상연구개발비의 지출효과가 3 년에 걸쳐 나타난 점을 들어 자본화할 필요성을 주장하였다.

Hirschey \& Weygandt[3]는 Hirschey(1982)의 연구를 발전시켜 기업의 연구개발비와 광고비 지출이 장기적으 로 자본시장에서 기업의 초과수익률에 기여하는가에 대 하여 실증적인 연구를 하였다. 분석결과, 연구개발비는 모두 초과시장가치에 정(+)의 영향이 미치는 것으로 분 석되었다.

우남수 외[4]는 자동차부품산업의 중요성과 공급사슬 상의 특성을 고려하여 국내 151 개 자동차부품 제조기업 을 대상으로 DEA를 통한 효율성 분석을 실시하였다. 투 입변수로는 제조원가, 자산, 자본금, 종업원 수, 공장면적 을 채택하였으며, 산출변수로는 매출액, 당기순이익, 고 객평가점수를 고려하였다. 상대적 분석을 위한 동질성 확 보하기 위해 전체 기업을 공급사슬상의 단계와 업종 단 위로 세분화하고 개별 그룹에서의 상대적 효율성을 측정 하였으며, 상대적 효율성 순위에 대한 통계적 타당성 분 석을 실시하였다. 위 선행연구들을 분석한 결과 각 그룹 에서 공통적으로 투입변수보다는 산출변수, 산출변수 중 에서는 당기순이익과 고객평가점수에 대한 개선 목표가 높은 것으로 파악되었으며, 업종별로는 단조와 용접의 경 우는 매우 유사한 개선목표를 가지고 있었다. 또한 프레 스의 경우는 당기순이익에 대한 개선목표가 낮은 반면 고객평가점수에 대한 목표는 상대적으로 높은 것으로 결 과를 도출하였다.

\section{2 효율성에 관한 이론적 고찰}

\subsection{1 효율성의 개념}


일반적으로 경제학 분야의 선행연구자들은 효율성 (efficiency)을 특정 조직단위가 자원을 활용하여 산출물 이나 결과물을 어떻게 창출해내는가를 표현할 때 사용해 왔다. 효율성은 자원의 사용에 대한 사용결과의 비율이 다. 생산조직이 사용한 투입요소의 사용량에 대한 산출물 의 생산량 비율을 의미한다.

효율성의 측정이 중요한 이유는 첫째, 효율성을 성공 의 지표로서 생산조직을 평가하는데 사용할 수 있다는 점과 둘째, 효율성을 측정한 후 생산 환경의 영향을 분리 함으로써 효율성의 차이의 원인에 관한 가설을 검정해볼 수 있다는 점이다. 효율성 차이의 원인을 파악하는 것은 성과를 개선하기 위한 공공 부문 및 민간 부문의 정책 및 전략수립에 필수적인 것이다. 또한 거시적 성과는 미시적 성과에 따라 달라지며 이러한 논리는 국가의 성장에 관 한 연구에 적용할 수 있다.

\subsection{2 효율성에 관한 선행연구}

경종수와 이보형[5]은 지역전략산업연계에 따른 중소 기업 지원정책의 효율성 개선방안을 연구하였다. 243 개 의 중소기업을 대상으로 효율성 분석을 실시하여 정책적 시사점을 제시하였다. 첫째, 전략산업별 차별화된 기업지 원 정책의 추진이 요구된다. 둘째, 실질적 성과중심의 기 업지원정책 추진이 요구된다. 셋째, 중소기업을 위한 기 술개발자금지원 확대 정책이 요구된다. 마지막으로 산학 연 연계사업의 활성화가 필요하다.

진경미와 윤병운[6]은 DEA모형을 이용하여 국내 대학 의 기술이전 효율성을 분석하였다. 분석결과, 일반 대학 보다 목적성이 있는 특화 대학에서 기술이전 효율성이 높은 것으로 분석되었고, 효율성 프론티어로 선정된 대학 의 수 역시 특화 대학이 많았다. 대학 TLO 육성 지원 사 업 참여 여부에 따른 대학에서의 기술이전의 효율성에는 유의한 차이가 없다는 점을 고려할 때, 국내에서 대학 $\mathrm{TLO}$ 육성 지원 사업이 성과를 내기 위해서는 시간이나 노력이 더욱 요구될 것이라고 하였다.

\subsubsection{DEA의 정의}

$\mathrm{DEA}$ 는 다수의 투입변수들(inputs)과 다수의 산출변수 들(outputs)을 고려하여 유사한 서비스를 제공하는 조직 의 효율성을 평가하는데 효과적인 선형계획기법이다. 통 계학적으로 회귀분석과는 달리 사전에 구체적인 함수형 태를 가정하고 모수(parameter)를 측정하는 것이 아니고 일반적으로 생산가능 집합에서 적용되는 몇 가지의 기준 하에서 평가대상의 경험적인 투입요소의 산출물간의 자 료를 이용해 경험적 효율성 프론티어를 평가대상으로 비 교하여 평가대상의 효율치를 측정하는 비모수적 접근방
법이다.

최근 들어 $\mathrm{DEA}$ 는 성과측정과 관련하여 새롭게 사용 되기 시작한 방법론으로 동일한 목적을 위해 다중 투입 물을 사용하여 다중산출물을 생산해 내는 DMU(Decision Making Unit, 의사결정단위)의 상대적 비효율성을 측정 하는 방법이다. 주어진 투입물과 산출을 이용하여 효율적 인 경계를 설정하고 경계상에 위치한 참조집합을 기준으 로 하여 개별 $\mathrm{DMU}$ 의 상대적 비효율성을 측정한다.

\subsubsection{DEA의 분석절차}

일반적으로 $\mathrm{DEA}$ 에서 가장 많이 활용되는 모델은 Charnes et al.[7]의 CCR(Charnesm-Cooper-Rhodes) 모델 과 Banker et al.[8]의 BCC(Banker-Charnes-Cooper) 모델 이다. 또한 $\mathrm{DEA}$ 는 투입요소에 초점을 두는가, 산출물에 초점을 두는가에 따라 투입지향(Input Oriented)과 산출지 향(Output Oriented)으로 구별된다. CCR 모델의 경우 투 입지향과 산출지향모델은 최소화 혹은 최대화하고자 하 는 요소가 무엇인지에 따라 결정될 사항일 뿐 투입지향 모델을 이용하든 산출지향모델을 이용하든 측정되는 효 율성은 항상 동일하다. 본 연구에서는 이러한 특성을 감 안하여 CCR 모델을 효율성분석 방법으로 채택하였다.

Fig. 1에는 분석절차에 대해 나타내었다.

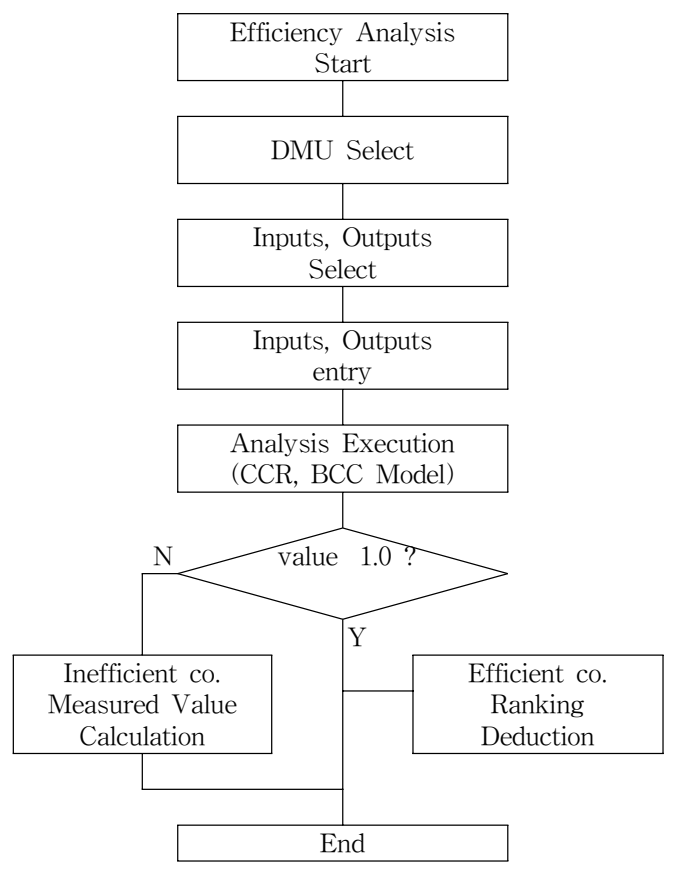

[Fig. 1] Analysis Procedure 


\section{3 효율성 분석}

\subsection{1 투입변수 및 산출변수의 선정}

선행 연구에서는 투입변수로 제조원가, 자산, 자본금, 종업원 수, 공장건물면적, 연구개발비 등을 사용하였으며 산출변수는 매출액, 당기순이익, 고객평가점수를 사용하 였다. 본 연구에서는 기존의 자동차산업의 효율성평가와 관련한 선행연구들에 대한 조사를 통해 가장 높은 빈도 로 사용된 변수들을 채택하였다.

일반적인 기업의 산출물은 매출액 또는 이윤이며 자동 차부품 제조기업의 경우에도 예외일 수 없다. 고객이 주 문하고 기업이 생산한 후 공급하면 공급한 수량에서 단 가를 곱하면 매출액이 되고, 매출액의 일정비율은 이윤이 라는 관점에서 산출변수의 첫 번째로 매출액을 선정하였 다. 또한, 기업의 경영활동 성과를 나타내는 당기순이익 은 경영자가 기업 활동을 통해 얻고자 하는 최종 목표 중 하나이다.

본 연구의 투입변수는 첫째, 자산이며 기업이 운영할 수 있는 가용자금의 총합계를 말한다. 자산은 그 성격에 따라 유동자산, 투자자산, 비유동자산으로 구분된다. 자 산은 매출액과 같이 기업 경영활동의 크기를 나타낼 수 있으며 규모의 효율성을 측정할 수 있다. 둘째, 종업원 수 는 비재무적 투입요소로 선행연구에서도 가장 많이 활용 된 변수이며 경영자원 중 노동력과 관련된 투입변수로 선정되었다. 셋째, 자동차 부품기업은 많은 인력이 투입 되고 그에 따른 인건비도 지불해야 한다. 종업원 수의 증 가와는 상관없이 능력이 향상될 때에도 인건비가 상승하 기 때문에 투입요소로 선정하였다.

\subsection{2 데이터 수집 및 표본의 선정}

본 연구는 다른 연구에 비해 자동차부품기업의 규모를 비슷한 기업들을 대상으로 분석하였다. 기업별 투입변수 와 산출변수가 거의 비슷한 조건으로 제약을 하였다. 특 히, 종업원 수를 100-300인 이하, 자산은 300-500억원 이 하, 자본은 300-400억원 이하, 매출액은 500-1,000억 원 이하인 기업을 대상으로 구분하였다.

따라서 비슷한 경쟁력, 시장성, 규모를 가진 기업 간의 상대적 효율성을 비교분석한다. 이를 위해 본 연구에서는 유사한 투입변수를 가지고 동일 또는 유사한 산출물을 생산, 제공하는 조직 간 상대적 효율성을 측정할 수 있는 $\mathrm{DEA}$ 기법을 활용하였다.

본 연구에서는 한국표준산업분류표를 바탕으로 자동 차 부품 제조업에 해당하는 중소기업으로 2013년 8월 기 준 코스피 및 코스닥에 상장된 25개 업체를 대상으로 분 석을 하였다. 투입변수로는 종업원 수, 인건비, 고정자산,
자본으로 선정하였고 산출변수로는 매출액 및 당기순이 익을 선정하였다.

분석 자료로 선정된 자동차부품기업은 총 25 개 기업 으로 종업원, 고정자산, 자본, 연구개발비, 인건비, 매출 액, 당기순이익을 Table 1 와 같이 나타내었다.

[Table 1] Inputs \& Outputs of Samples

\begin{tabular}{c|c|c|c}
\hline \multicolumn{3}{c|}{} & SME \\
\hline \hline \multirow{4}{*}{ Inputs } & Employee & IE & 25 \\
\cline { 2 - 4 } & Fixed Asset & IFA & 210 \\
\cline { 2 - 4 } & Capital & IC & 41,086 \\
\cline { 2 - 4 } & Labor Cost & ILC & 35,135 \\
\hline \multirow{3}{*}{ Outputs } & Sales & OS & 2,580 \\
\cline { 2 - 4 } & Net Income & ONI & 85,300 \\
\hline
\end{tabular}

\subsection{3 상관관계 분석}

상관분석을 한 결과를 Table 2 와 같이 나타내었다. 종 업원, 고정자산, 자본, 연구개발비, 인건비, 매출액, 당기 순이익은 서로 상관관계가 있는 것으로 나타났다. $\mathrm{p}$ 값들 이 대부분 0.01 보다 낮아서 투입요소와 산출요소간의 상 관관계가 매우 높음을 알 수 있다.

[Table 2] Inputs \& Outputs of Samples

\begin{tabular}{c|c|c|c|c|c|c}
\hline & IE & IFA & IC & ILC & OS & ONI \\
\hline \hline IE & 1 & - & - & - & - & - \\
\hline IFA & $.730^{* *}$ & 1 & - & - & - & - \\
\hline IC & $.631^{* *}$ & $.694^{* *}$ & 1 & - & - & - \\
\hline ILC & $.741^{* *}$ & $613^{* *}$ & $.464^{*}$ & 1 & - & - \\
\hline OS & $.692^{* *}$ & $.837^{* *}$ & $.759^{* *}$ & $.520^{* *}$ & 1 & - \\
\hline ONI & $.494^{*}$ & $.397^{*}$ & $.765^{* *}$ & .213 & .395 & 1 \\
\hline \multirow{2}{**}{, $\mathrm{p}<0.01 ; *, p<0.05$}
\end{tabular}

\subsection{4 효율성평가 결과}

$\mathrm{CCR}$ 모델을 이용하여 자동차부품기업의 효율성을 분 석한 결과 평균 효율성은 0.808 의 수치를 나타냈고, $\mathrm{BCC}$ 모델의 효율성 분석결과는 평균 효율성 0.895 의 수치를 보이고 있다. Table 3 과 같이 CCR 모델의 효율성보다 $\mathrm{BCC}$ 모델의 효율성이 0.087 큰 것으로 나타났다.

[Table 3] CCR, BCC Effectiveness Comparison

\begin{tabular}{c|c|c}
\hline Division & CCR Model & BCC Model \\
\hline \hline Mean & 0.808 & 0.895 \\
\hline Max & 1.000 & 1.000 \\
\hline Min & 0.485 & 0.538 \\
\hline S.D. & 0.173 & 0.141 \\
\hline Efficient DMU & 6 & 12 \\
\hline Inefficient DMU & 19 & 13 \\
\hline Total DMU & 25 & 25 \\
\hline
\end{tabular}


$\mathrm{CCR}$ 모델의 경우 전체 25 개의 기업 중 효율적인 $\mathrm{DMU}$ 가 6개, 비효율적인 DMU가 19개로 나타났다. BCC 모델의 경우는 전체 25 개 기업 중 효율적인 $\mathrm{DMU}$ 가 12 개, 비효율적인 $\mathrm{DMU}$ 가 13 개로 나타나고 있어, $\mathrm{CCR}$ 모 델보다는 높은 효율성 수치를 보여주고 있다.

\subsection{5 비효율성 기업의 원인분석}

자동차부품기업의 효율성 평균값은 $\mathrm{CCR}$ 모델로 측정 한 총기술효율성이 $0.808, \mathrm{BCC}$ 모델로 측정한 순수기술 효율성이 0.895 , 기술효율성을 순수기술효율성으로 나눈 규모효율성이 0.905 으로 나타냈다. 자동차부품기업의 효 율성 측정(CCR, $\mathrm{BCC}$ 효율성)에서 모두 효율성이 1 인 기 업은 기술효율성, 순수기술효율성, 규모효율성이 모두 1 인 동일한 값을 갖는다. 규모의 비효율성이 존재하는 것 은 효율적 집합이 $\mathrm{BCC}$ 모델에 있으나 비효율적 집합이 $\mathrm{CCR}$ 모델이 있는 기업의 경우 순수기술효율성만 만족하 고 규모효율성은 충족되지 못하기 때문이라고 해석할 수 있다.

자동차부품기업의 효율성 규모가 $\mathrm{DMU}$ 의 효율성에 영향을 미칠 수 있음을 고려하여 규모에 의한 비효율성 을 파악하기 위해 DMU의 규모수익변동을 가정하고, 기 술효율성을 다시 순수기술효율성과 규모효율성으로 구분 하였다. 순수기술효율성은 생산조직을 생산가능곡선상의 조합으로 생산하고 있는지 여부에 해당하는 것이고, 규모 효율성은 생산과정에서 최소의 비용이 발생하는 규모를 채택하고 있는지를 나타내는 것이다.

Table 4에는 CCR 모델과 BCC 모델을 이용하여 측정 된 순수기술효율성과 규모효율성 값을 비교하여 비효율 적인 자동차부품기업의 비효율성 원인을 정리하였다. 또 한, 규모의 효율성은 변동규모수익과 불변규모수익 가정 하의 각 $\mathrm{DMU}$ 별 투입과 산출구조를 비교하기 위해 $\mathrm{CCR}$ 효율성과 $\mathrm{BCC}$ 효율성을 모두 계산하며 이들의 비율로 정의된다. 이 비율이 1 보다 작으면 규모효율성이 존재하 고 1 이면 현재의 작업규모가 최적인 것으로 판단한다.

[Table 4] CCR, BCC Effectiveness Comparison

\begin{tabular}{c|c|c|c}
\hline $\begin{array}{c}\text { Returns } \\
\text { to Scale }\end{array}$ & DMU & $\begin{array}{c}\text { Inefficiencies } \\
\text { Cause }\end{array}$ & DMU \\
\hline \hline CRS & 6 & PTE & 10 \\
\hline DRS & 7 & SE & 9 \\
\hline IRS & 12 & - & - \\
\hline Total & 25 & Total & 19 \\
\hline
\end{tabular}

Table 4에 의하면 자동차부품기업의 비효율성 원인이 기술적 요인이 10 개, 규모의 문제가 9 개로 비효율성 기업
의 19 개 중 $47.4 \%$ 가 규모의 요인에 의한 비효율임을 알 수 있다. 또한, 규모수익은 불변규모수익이 6개이고, 체 감규모수익이 7개이며, 체증규모수익이 12 개로 나타났다.

$\mathrm{DEA}$ 분석결과 비효율적으로 나타난 $\mathrm{DMU}$ 들이 효율 적인 DMU가 되기 위해 벤치마킹해야 할 대상이 Table 5 에 제시되어 있고 자동차부품기업의 참조집합 출현빈도 를 나타내고 있다. 효율적 $\mathrm{DMU}$ 의 신뢰도는 참조횟수에 따라 판단될 수 있다. 이는 준거집단으로 출현한 횟수가 많은 DMU 일수록 효율적일 가능성이 높다는 것이다. 효 율성이 1 인 6 개 준거집단을 살펴보면 $\mathrm{DMU} 1,5,7,10$, 18,24 의 참조횟수가 각각 $11,6,6,18,3,11$ 로 많음을 알 수 있다. DMU 10이 DMU 1보다 참조횟수가 많아 상 대적으로 신뢰성이 높다고 할 수 있다.

[Table 5] Frequency Reference Set

\begin{tabular}{c|c|c}
\hline DMU & Efficiency & Reference Count \\
\hline \hline F1 & 1.000 & 11 \\
\hline F5 & 1.000 & 6 \\
\hline F7 & 1.000 & 6 \\
\hline F10 & 1.000 & 18 \\
\hline F18 & 1.000 & 3 \\
\hline F24 & 1.000 & 11 \\
\hline
\end{tabular}

\subsection{5 초효율성 순위}

효율성 분석은 효율적인 $\mathrm{DMU}$ 와 혹은 비효율적인 $\mathrm{DMU}$ 에 대한 분석에 그치고 있다. 만약 효율적인 DMU 들 간의 상대적 효율성 순위를 파악하고자 한다면 앞서 분석한 $\mathrm{CCR}$ 모델과 $\mathrm{BCC}$ 모델은 적합하지 않다. 이러한 경우에 사용되는 방법이 DEA 순위 분석으로 본 연구에 서는 Super-Efficiency Ranking 방법을 이용하였다. DEA 분석에서 효율적인 $\mathrm{DMU}$ 들은 1 의 값으로 측정된다. 따라 서 효율적, 비효율적인 두 개의 집단으로 구분하게 될 뿐 이고, 효율적인 DMU간의 순위 정보를 알 수 없다는 한 계를 극복하기 위해, 자동차부품기업의 초효율성 순위와 점수정보를 도출하여 객관적인 순위정보를 제공하고자 한다.

초효율성 기법은 효율적 DMU에 대한 순위를 제공하 기 위한 것으로 효율적 $\mathrm{DMU}$ 가 현재의 효율성을 유지하 면서 투입벡터를 비례적으로 얼마나 증가시킬 수 있는가 를 측정하는 것이며 이러한 경우 효율성 값은 1 보다 커질 수 있다. 이것은 측정대상 $\mathrm{DMU}$ 로부터 그 $\mathrm{DMU}$ 를 제외 한 상태에서 추정된 효율적 프론티어까지의 거리를 측정 하는 것으로 본래의 DEA 모델에서 비효율적 $\mathrm{DMU}$ 를 평 가하는 것과 유사한 방법으로 효율적 $\mathrm{DMU}$ 를 평가하는 것이다. 비효율적인 $\mathrm{DMU}$ 들은 처음의 $\mathrm{CCR}$ 모델과 $\mathrm{BCC}$ 
모델에서 계산된 효율성 값은 그대로 유지되고 효율적인 $\mathrm{DMU}$ 에 대해서만 새로운 초효율성 값으로 산출할 수 있 다. 초효율성 값은 효율적인 집합을 구성하는 $\mathrm{DMU}$ 들의 투입벡터의 투입량을 증분 하였을 경우 $\mathrm{CCR}$ 모델에서 산출된 효율성 1 을 유지할 수 있는 것을 의미한다.

자동차부품기업 중 초효율성 1순위인 DMU 24번의 경우 $\mathrm{CCR}$ 모델에서 투입요소의 조합을 2.0 배 이상 늘려 도 효율성 1이 달성될 수 있음을 의미하므로 DMU 24번 은 다른 표본과제에서 얻어진 프론티어에 미치는 영향이 매우 큰 DMU임을 확인할 수 있다. Table 6에서 자동차 부품기업의 초효율성 순위와 점수를 제시하였다.

[Table 6] Super-Efficiency Analysis

\begin{tabular}{c|c|c}
\hline Rank & DMU & Efficiency \\
\hline \hline 1 & F24 & 2.094 \\
\hline 2 & F5 & 1.252 \\
\hline 3 & F7 & 1.248 \\
\hline 4 & F10 & 1.235 \\
\hline 5 & F18 & 1.234 \\
\hline 6 & F1 & 1.211 \\
\hline
\end{tabular}

\section{3. 결론}

\section{1 연구의 결론}

본 연구에서는 DEA 모델을 이용하여 규모와 경쟁력 이 비슷하다고 판단된 자동차부품 중소기업 중 코스피와 코스닥에 상장된 25 개의 업체를 대상으로 DEA 분석기법 을 활용하여 각 기업에 대한 상대적 효율성을 분석하였 다. 효율성분석에 사용된 산출변수는 매출액, 당기순이익 이었으며 투입변수로는 종업원 수, 고정자산, 자본, 인건 비가 사용되었다. 또한 효율성 분석에 있어서는 $\mathrm{CCR}$ 모 델과 더불어 기업 규모를 고려한 $\mathrm{BCC}$ 모델을 통해 분석 하였으며 효율적인 기업의 순위 분석에는 초효율성 모델 을 이용하여 효율성의 차이에 의한 기업의 순위를 분석 하였다.

본 연구의 분석결과를 토대로 결과를 요약하면 다음과 같다. 첫째, 효율성분석결과 $\mathrm{CCR}$ 모델에서는 전체 25 개 기업 중 6 개 기업이 효율적인 것으로 나타났지만 기업의 규모를 고려한 효율성 분석인 $\mathrm{BCC}$ 분석결과 12 개 기업이 효율적으로 운영하는 것으로 나타났다. 둘째, 25 개의 자 동차부품기업 중 효율성이 1 인 기업이 $\operatorname{DMU~} 1,5,7,10$, 18,24 로 나타났으며, 다른 자동차부품기업이 상대적으로 벤치마킹을 해야 할 대상은 DMU $1,10,24$ 이다.

\section{2 연구의 시사점 및 한계}

본 연구의 결과를 바탕으로 시사점을 정리하면 다음과 같다. 첫째, 경쟁력이 비슷한 국내 자동차부품기업의 효 율성을 실증적으로 분석하여 경영효율성을 제시한 것은 향후 자동차부품기업을 경영하는데 있어 매우 중요한 정 보를 제공하였다고 할 수 있다. 둘째, 자동차부품산업의 생산성과 지속적 발전을 위해 실무적인 가치가 있다고 할 수 있다.

본 연구의 한계는 다음과 같다. 첫째, 수식 모델에 의 존하는 DEA 연구의 특성상 다양한 투입 및 산출요소를 이용해야 하며 분석 표본에 따라 효율성 결과가 변하는 점은 $\mathrm{DEA}$ 모델을 이용한 효율성 분석의 단점이라 할 수 있다. 둘째, 본 연구에서의 투입요소와 산출요소는 선행 연구를 바탕으로 설정하였으나 자동차부품산업의 특성을 모두 반영하지 못했다. 이러한 연구의 한계점을 바탕으로 향후 연구는 다양한 투입 및 산출요소를 활용하여 연구 를 수행하고자하며 세계 자동차부품기업을 비교분석하고 자 한다.

\section{References}

[1] Hana Institute of Finance(2012), "Auto Parts Industry Trends and Analysis of Group-Type Risk Factors", Industry Information, Vol.4, pp.1-39.

[2] Keun-Hyo, Yook(2003), "A Further Examination on the Economic Impacts of Advertising and R\&D Expenditures", Journal of Business Research, Vol.18, No.3, pp.219-251.

[3] Hirschey, M. and Weygandt, J. J.(1985), “Amortization Policy for Advertising and Research and Development Expenditure", Journal of Accounting Research, Vol. 23, No. 1, pp.326-335.

DOI: http://dx.doi.org/10.2307/2490921

[4] Nam-Soo, Woo, Sang-Hum, Yoon, Jong-Hun, Park(2010), "A Study on the Efficiency Analysis for the Automobile Parts Manufactures", Journal of Decision Science, Vol.18, No.1, pp.1-20.

[5] Jong-soo, Kyung, Bohyung, Lee(2010), "A Study of Business Support Policy for Small-Medium Enterprises in Regional Strategic Industry", Journal of the Korea Academia-Industrial cooperation Society, Vol.11, No.6, pp.2030-2037.

DOI: http://dx.doi.org/10.5762/KAIS.2010.11.6.2030

[6] Gyung-mi Jin, Byun-gun Yoon(2012), "A study on the efficiency measurement of University's technology 
transfer by DEA model", Journal of the Korea Academia-Industrial cooperation Society, Vol.13, No.6, pp.2558-2569.

\section{유 왕 진(Wang-Jin Yoo)}

[정회원]
DOI: http://dx.doi.org/10.5762/KAIS.2012.13.6.2558

[7] Charnesm A., W. W. Cooper and E. Rhodes(1981), "Evaluation Program and Managerial Efficiency : An Application of Data Envelopment Analysis to Program Follow Through", Management Science, Vol.27 No.6, pp.669 697.

[8] Banker, R. D., A. Charnes, W. W. Cooper(1984), "Some Models for Estimating Technical and Scale Inefficiencies in Data Envelopment Analysis," Management Science, Vol.30, No.9, pp.1078-1092. DOI: http://dx.doi.org/10.1287/mnsc.30.9.1078

\section{조 형 국(Hyung-Kook Cho)}

[정회원]

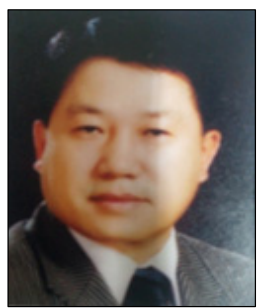

1976년 2월 : 서울대학교 공과대 학 공업교육학과 (금속공학석사)

- 1979년 2월 : 한양대학교 산업대 학원 기계공학과 (기계공학석사)

- 2009년 2월 : 건국대학교 일반대 학원 벤처전문기술학과 (박사과 정 수료)

- 2012년 10월 현재 : (주) 제로 하이텍 사장

<관심분야>

기계공학, 벤처기술경영

\section{이 철 규(Cheol-Gyu Lee)}

[정회원]

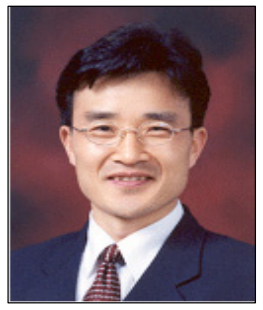

- 1987년 2월 : 건국대학교 산업공 학과 (학사)

- 1991년 2월 : 일본 게이오대학교 관리공학 (공학석사)

- 1997년 2월 : 일본 게이오대학교 바이오기술 (공학박사)

- 2004년 9월 현재 : 건국대학교 벤처창업지원센터장, 건국대학교 벤처전문기술학과 주임교수, 신

<관심분야> 산업융합학과 교수

벤처기술경영, 벤처창업

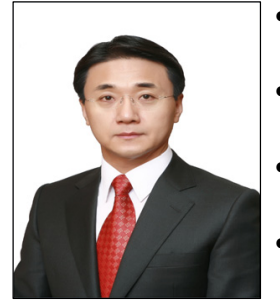

- 1984년 2월 : 건국대학교 산업공 학과 (학사)

- 1986년 2월 : 미시간웨인주립대 학교 산업 및 제조공학과 (석사)

- 1990년 2월 : 미시간웨인주립대 학교 산업 및 제조공학과 (박사)

- 1997년 3월 현재 : 건국대학교 산업공학과, 벤처전문기술학과, 신산업융합학과 교수, 벤처테크 <관심분야> 노경영스쿨 총괄교수

산업공학, 기술경영 